\title{
WHAT IS IT: HAEMANGIOMA OR VASCULAR MALFORMATION?
}

\author{
University of Cyprus, Medical School, Cyprus \\ Contact: Ivona Đorđević \\ Pediatric surgery and orthopedics clinic, Clinical Center Niš \\ Boul. Nemajić 48,18000 Niš, Serbia \\ Mobile: +381652214561 \\ E-mail: ivonadj74@gmail.com
}

Zacharias Zachariou

\begin{abstract}
Congenital vascular anomalies constitute a large group of lesions in children, and they differ in terms of their localization, outer appearance, as well as histology. Additionally, the nomenclature of this group of lesions has been confusing due to the indiscriminate and interchangeable use of the term haemangioma and vascular malformation in diagnosis and management. Whilst hemangiomas are true endothelial cell neoplasms, vascular malformations are localized congenital defects of vascular morphogenesis.

The aim of this article is to overcome obstacles in communication when describing a vascular lesion by adhering to the correct terminology. This leads inevitably to the correct therapeutic guidelines, management and follow-up of these lesions. The therapy guidelines, management and follow-up of hemangiomas and vascular malformations differ and are beyond the scope of this article. Acta Medica Medianae 2017;56(2):111-114.
\end{abstract}

Key words: congenital haemangioma classification, haemangioma, infantile hemangioma, vascular anomalies, vascular malformation 